\title{
The new scalar politics of evaluation: An emerging governance role for evaluation
}

David Rutkowski, Jason Sparks

Graduate School of Education

\section{Abstract}

In this article we analyze how roles for evaluation are described and argued for in key texts produced and/or promoted by three influential international networks: the High Level Forum on Aid Effectiveness; the Organisation for Economic Cooperation and Development Assistance Committee's Network on Development Evaluation; and the Network of Networks for Impact Evaluation. We contend that these complex multilateral networks are working supranationally through soft power to promote: common standards of evaluation practice; a dominant model of evaluation (impact evaluation); and new evaluation roles, relationships and practices for the field of development. Moreover, we argue that this emerging complex multilateral agenda for evaluation may position evaluation and evaluators within a global governance strategy allowing greater influence to international development organizations. We conclude with a discussion of the implications of the analysis for evaluators working in the field of international development.

$\begin{array}{ll}\text { Original language } & \text { English } \\ \text { Pages (from-to) } & 492-508 \\ \text { Number of pages } & 17 \\ \text { Journal } & \text { Evaluation } \\ \text { Volume } & 20 \\ \text { Issue number } & 4 \\ \text { State } & \text { Published - Oct 12 2014 }\end{array}$

Rutkowski, D., \& Sparks, J. (2014). The new scalar politics of evaluation: An emerging governance role for evaluation. Evaluation, 20(4), 492-508. DOI: 10.1177/1356389014550561 